\title{
Local adaptation for body color in Drosophila americana: commentary on Wittkopp et al.
}

Heredity (2011) 106, 904-905; doi:10.1038/hdy.2010.141; published online 10 November 2010

Wittkopp et al. (2011) report clinal variation of cuticle coloration among populations of Drosophila americana despite the high levels of gene flow across collection sites, providing evidence for local (darwinian) adaptation of body coloration in this species. Several mechanisms have been proposed to explain the evolutionary patterns of pigment variation in ectothermic organisms such as D. americana. For example, the occurrence of dark-pigmented populations of several Drosophila spp. has been associated with dry environments (for example, Parkash et al., 2010). This relationship represents the main hypothesis tested by Wittkopp et al. (2011), and the authors conclude that pigmentation and desiccation resistance are not unequivocally linked among the populations investigated. However, other climatic explanations that are not addressed in the study may explain these color patterns. For example, the thermal melanism hypothesis (TMH) suggests that if all else is equal, darker individuals may heat up faster and reach higher equilibrium temperatures than lighter individuals, providing a benefit in cooler conditions (Clusella-Trullas et al., 2007). Recently, the $\mathrm{TMH}$ has received support at several spatial scales in reptiles (Clusella-Trullas et al., 2008, 2009) and has also been demonstrated in many insect species (for example, Brakefield and Willmer, 1985; reviewed in Clusella-Trullas et al., 2007). Wittkopp et al. (2011) showed that longitude was a better explanatory variable than environmental relative humidity. However, latitude and longitude are typically used as proxies of climate (for example, temperature and humidity) and site (topography) variation. The use of longitude as a predictor of pigment variation does not indicate which climate variables (or interactions thereof) might best explain the patterns observed, and therefore provides little insight into the potential evolutionary mechanisms at work.

Using the data from Wittkopp et al. (2011), we reanalyzed their largest dataset (Table 1, dataset A, p 6), seeking the most likely climatic explanation for the observed geographic variation in pigment intensity (with light-colored populations having higher values of pigment intensity than darker populations). We used an information-theoretic model selection approach (Burnham and Anderson, 2002) to address both the TMH and the desiccation resistance hypothesis as potential explanations. The best model, judged from its Akaike information criterion (AIC) value, includes solar radiation and mean diurnal temperature range as explanatory variables (Table 1). The results of our analyses indicate that this explanatory model has a $43.1 \%$ probability of being the best model out of all those compared (as indicated by the model Akaike weights, $w_{i}$ ) (Table 1). By contrast, longitude as a single predictor also has some support $(\triangle \mathrm{AIC}=2)$, but a much lower probability of being the best model (Burnham and Anderson, 2002). Nonetheless, the best model indicates that the relationship between $D$. americana pigmentation intensity and solar radiation is positive and in line with the TMH. Darker populations tend to be in areas with lower solar radiation and mean diurnal temperature range compared with lighter populations. Therefore, these relationships suggest that, in cooler environments, being dark could be an advantage as individuals may heat up faster and reach preferred body temperatures sooner, thereby increasing the activity time. Additional population data on pigmentation of D. americana across a broader range of microclimates and incorporating cuticle reflectance across the full spectrum of solar radiation (ultraviolet, visible and near-infrared) may help distinguish among competing hypotheses for color variation in ectotherms. It is clear from our analyses of Wittkopp et al.'s (2011) data that the TMH may provide the major explanation for color variation in D. americana and requires closer scrutiny. Nevertheless, and in agreement with Wittkopp et al. (2011), it seems that the desiccation resistance hypothesis is an unlikely explanation in this species. Studies should consider both hypotheses simultaneously when attempting to explain pigment variation of ectotherms in relation to climate. A strong inference approach with multiple working hypotheses (see, for example, Huey et al., 1999) may provide a suitable way forward in future.

Table 1 The ten best environmental climate models of 28 models tested explaining variation in pigmentation intensity among Drosophila americana populations from dataset A in Wittkopp et al. (2011)

\begin{tabular}{clcc}
\hline Rank & Model & AIC & $\mathrm{w}_{\mathrm{i}}$ \\
\hline 1 & SOLRAD+MDTR & 92.040 & 0.431 \\
2 & MDTR & 93.993 & 0.162 \\
3 & LONG & 94.090 & 0.155 \\
4 & SOLRAD+TMIN+SOLRAD*TMIN & 95.787 & 0.066 \\
5 & LAT+LONG & 96.033 & 0.058 \\
6 & LAT+LONG+LAT*LONG & 97.950 & 0.022 \\
7 & RH+SOLRAD+SOLRAD*RH & 98.220 & 0.020 \\
8 & SOLRAD+APP+MAT & 98.513 & 0.017 \\
9 & SOLRAD+TMIN & 98.725 & 0.015 \\
10 & SOLRAD+APP+TMIN & 99.688 & 0.009
\end{tabular}

Abbreviations: AIC, Akaike information criterion; APP, mean annual precipitation $(\mathrm{mm})$; LAT, latitude $\left({ }^{\circ}\right)$; LONG, longitude $\left(^{\circ}\right)$; MAT, mean annual temperature $\left({ }^{\circ} \mathrm{C}\right)$; MDTR, mean diurnal temperature range $\left({ }^{\circ} \mathrm{C}\right) ; \mathrm{RH}$, relative humidity (\%); TMIN, minimum temperature of the coldest month $\left({ }^{\circ} \mathrm{C}\right) ; w_{\mathrm{i}}$, Akaike weight. Climate variables were extracted from http://www.worldclim.org (at 2.5 arc min resolution) for data gathered over 1950-2000 and mean annual solar radiation (SOLRAD, $\mathrm{W} \mathrm{m}^{-2}$ ) was obtained from the IPCC Data Distribution Centre $\left(0.5^{\circ}\right.$ resolution). Only non-collinear variables were included in each model. 


\section{Conflict of interest}

The authors declare no conflict of interest.

S Clusella-Trullas ${ }^{1}$ and JS Terblanche ${ }^{2}$ ${ }^{1}$ Centre for Invasion Biology, Faculty of Science, Stellenbosch University, Stellenbosch, South Africa and ${ }^{2}$ Conservation Ecology \& Entomology Department, Faculty of AgriSciences, Stellenbosch University, Stellenbosch, South Africa

E-mail: jst@sun.ac.za

\section{References}

Brakefield PM, Willmer PG (1985). The basis of thermal melanism in the ladybird Adalia bipunctata: differences in reflectance and thermal properties between the morphs. Heredity 54: 9-14.
Burnham KP, Anderson DR (2002). Model Selection and Multimodel Inference: A Practical Information-Theoretic Approach, 2nd edn. Springer: New York.

Clusella-Trullas S, Terblanche JS, Blackburn TM, Chown SL (2008). Testing the thermal melanism hypothesis: a macrophysiological approach. Funct Ecol 22: 232-238.

Clusella-Trullas S, van Wyk JH, Spotila JR (2007). Thermal melanism in ectotherms. J Thermal Biol 32: 235-245.

Clusella-Trullas S, van Wyk JH, Spotila JR (2009). Thermal benefits of melanism in cordylid lizards: a theoretical and field test. Ecology 90: 2297-2312.

Huey RB, Berrigan D, Gilchrist GW, Herron JC (1999). Testing the adaptive significance of acclimation: a strong inference approach. Am Zool 39: 323-336.

Parkash R, Kalra B, Sharma V (2010). Impact of body melanisation on contrasting levels of desiccation resistance in a circumtropical and a generalist Drosophila species. Evol Ecol 24: 207-225.

Wittkopp PJ, Smith-Winberry G, Arnold LL, Thompson EM, Cooley AM, Yuan DC et al. (2011). Local adaptation for body color in Drosophila americana. Heredity 106 592-602. 